This is guidance that should have a home in every dental practice in the land irrespective of its practising arrangements

\title{
Everyone's responsibility
}

There is, I understand, a proverb to the effect that "It takes a whole village to bring up a child." It has a folksy sort of feel about it which brings to mind a type of community Elysium with visions of happy childhoods, of perhaps misdemeanours that are recorded but forgiven, of a group responsibility which is supportive and understanding of individual frailties and social shortcomings. More importantly it suggests that it is possible for group action to create a positive outcome.

In a distinctly less romantic light and in a harsher world than that of an idealised hamlet of yore, child protection is an issue that does involve everyone in the village and particularly in this instance, us and our dental team members. The launch of a new resource at the recent British Dental Conference in Birmingham, entitled Child protection and the dental team, is to be welcomed as a very valuable guide as to how to deal with the bewildering, distressing and undeniably awkward occurrence of suspected child abuse.

It often said of us, as dentists, in various contexts that we are in a unique position amongst health care professionals as we see people on a regular basis, whether they require treatment or not. Although usually quoted in a somewhat detached way I would also add that far more significantly we also have a continuing personal relationship with our patients, which enables us to detect changes in their oral health, of course, and well-being in general. A truly unique and especially valuable position.

Therefore, in the context of detecting possible child abuse and neglect we are particularly well placed and it is our responsibility to be both vigilant and fully aware of the next steps that we need to take in the event that our suspicions are aroused. However, these are not easy or pleasant tasks. Indeed, as recent correspondence to this journal has indicated, well meaning actions can be met with unlooked for consequences and I suspect that we will be receiving further letters on this subject that will expand on our collective experiences.
This is why the new resource is to be particularly welcomed since it not only provides detailed guidance on what to be aware of and then to carefully observe, but also how to proceed, who to contact and exactly what to do. It has been sent to all NHS dental practices in England, as it was commissioned and funded by the Department of Health and because the detailed procedural guidance in terms of response to suspected incidents is written for the situation as it relates to English legislation. However, the core messages are pertinent to practices throughout the UK and, very much as importantly, to practices outside the NHS.

I have heard it said by colleagues that they really do not need guidance on child abuse as they have a 'private practice.' Do not be fooled and do not be complacent. Although child abuse and neglect are often regarded as being associated with families living in adverse social environments, due perhaps to poverty, social isolation or poor housing or education, parents and others who commit such acts do not come only from such circumstances. Tragically, but realistically, no social group has the exclusivity on abuse of this type. Indeed the more subtle but nonetheless distressing condition of emotional abuse is clearly not the sole preserve of those living in poorer social conditions. Private practices are not immune from such experiences. Be assured that this is guidance that should have a home in every dental practice in the land irrespective of its practising arrangements.

Above all the fine words about responsibility, ethics, duty and procedures what we all have to remember very clearly is that this matter is about the welfare of children, and that is something we may not shirk, as a village or as individuals.

1. Harris $J$ et al. Child protection and the dental team. London, Department of Health, 2006. ISBN 095522570 1. www.cpdt.org.uk doi: $10.1038 /$ sj.bdj.4813696 